\title{
High-pressure spark plasma sintering of MgO-doped transparent alumina
}

\author{
Byung-Nam KIM, ${ }^{\dagger}$ Keijiro HIRAGA, Salvatore GRASSO, Koji MORITA, \\ Hidehiro YOSHIDA, Haibin ZHANG and Yoshio SAKKA \\ National Institute for Materials Science, 1-2-1 Sengen, Tsukuba, Ibaraki 305-0047, Japan
}

Transparent alumina doped with MgO is fabricated by spark plasma sintering (SPS) under high pressures. An optimum sintering condition explored by changing the combination of the applied pressure and sintering temperature led to an in-line transmission close to the maximum reported for alumina in earlier studies. The effects of pressure on both grain size and transmission are strongly dependent on the sintering temperature: negligible effect at low temperatures and significant effect at high temperatures. (02012 The Ceramic Society of Japan. All rights reserved.

Key-words : Alumina, Spark plasma sintering, Transmission, Grain size, Pressure

[Received November 2, 2011; Accepted January 6, 2012]

\section{Introduction}

Spark plasma sintering (SPS) has been emerged as a novel technique to fabricate transparent ceramics. By the electric current applied directly to powder compacts under pressure, this technique facilitates rapid heating, suppressed grain growth and high densification rate, and accordingly the fabrication of transparent ceramics having high density and fine microstructure at relatively low temperatures. Transparent alumina ceramics were also fabricated using SPS, and the transparency has been improved by optimizing the sintering conditions such as heating rate, ${ }^{1), 2)}$ sintering temperature, ${ }^{3), 4)}$ cation doping, ${ }^{4)-6)}$ powder treatment ${ }^{7)}$ and pressure. ${ }^{8)}$ In particular, Grasso et al. ${ }^{8)}$ recently applied high pressure $(500 \mathrm{MPa})$ during SPS of pure alumina and reported an in-line transmission of $64 \%$ at a wavelength of $640 \mathrm{~nm}$ for $0.8-\mathrm{mm}$ thick sample. This value is the highest transmission among alumina ceramics obtained by SPS, so that the application of high pressure is one of the most effective ways to obtain highly transparent alumina. Nevertheless, the maximum transmission obtained by SPS at $500 \mathrm{MPa}$ is still lower than that $(72 \%)$ attained by HIP at $200 \mathrm{MPa} .{ }^{9), 10)}$ The lower transmission may be attributed to grain growth during sintering. Although the pure alumina was sintered at quite low temperatures $\left(1000^{\circ} \mathrm{C}\right)$, the grains grew into sizes more than 2 times as large as those of the source powder. Hence, it is expected that the suppression of grain growth during SPS should improve the transmission properties.

For the suppression of grain growth in alumina, the doping of $\mathrm{MgO}$ is known well. ${ }^{4), 11)}$ In the present study, the MgO-doped alumina is sintered using SPS under high pressures. The effects of pressure and sintering temperature are examined to find optimum sintering conditions and to improve the transmission properties of alumina.

\section{Experimental procedures}

Commercial $\alpha-\mathrm{Al}_{2} \mathrm{O}_{3}$ powder (TM-DAR, Taimei Chemicals Co., Ltd., Japan) with a purity of $99.99 \%$ and a particle size of $100-150 \mathrm{~nm}$, was used in the present study. The $\mathrm{Al}_{2} \mathrm{O}_{3}$ powder

\footnotetext{
Corresponding author: B.-N. Kim; E-mail: kim.byung-nam@nims. go.jp
}

was mixed in ethanol with $0.03 \mathrm{wt} \% \mathrm{MgO}$ (100A, Ube Industries, Ltd., Japan) with a purity of $99.97 \%$ and an average particle size of $17 \mathrm{~nm}$. After drying and granulation using a 60-mesh sieve, the mixed powder was poured into a graphite die, and pressed by a $10-\mathrm{mm}$ diameter graphite punch. In order to achieve high pressures, the die is composed of larger outer and smaller inner graphite dies. ${ }^{12)}$ The graphite die and punch were heated to the sintering temperature $\left(1000-1300^{\circ} \mathrm{C}\right)$ at a rate of $10^{\circ} \mathrm{C} / \mathrm{min}$ from $700^{\circ} \mathrm{C}$ under a uniaxial pressure of $50-400 \mathrm{MPa}$ in vacuum $\left(10^{-3}\right.$ torr) using a spark plasma sintering machine (SPS-1050, Sumitomo) with a pulse duration of $3.4 \mathrm{~ms}$. The heating was conducted using a sequence consisting of twelve DC pulses $(40.8 \mathrm{~ms})$ followed by no current for $6.8 \mathrm{~ms}$. The temperature was measured by an optical pyrometer focused on the nonthrough hole (1-mm diameter and 2-mm depth) in the graphite die. After holding for $20 \mathrm{~min}$ at the sintering temperature, the mechanical pressure was removed, and the sintered body was subsequently annealed at $800-1000^{\circ} \mathrm{C}$ for $10 \mathrm{~min}$ inside the SPS machine in order to reduce the residual stress caused by the pressure applied during sintering. Finally, we obtained a sintered disk with a diameter of $10 \mathrm{~mm}$ and a thickness of $3 \mathrm{~mm}$.

The sintered body was ground to a thickness of $1 \mathrm{~mm}$ and carefully mirror-polished on both sides using a diamond slurry. The in-line transmission was measured in the wavelength range of 240-1600 nm using a double-beam spectrophotometer (SolidSpec-3700DUV, Shimadzu) equipped with an integrating sphere. The measured optical properties vary within a $3 \%$ scattering depending on the position of the sample. For each specimen polished and thermally etched at a temperature $100-200^{\circ} \mathrm{C}$ below the sintering temperature, microstructural observation was conducted using a scanning electron microscope (SEM) (JSM-6500, JEOL). The grain size was measured by obtaining the average cross section area per grain and by assuming spherical grains. The measured grain size is an apparent one, so that it was multiplied by 1.225 to determine the true grain size.

\section{Results and discussion}

The in-line transmission of the transparent alumina sintered at various temperatures and pressures is shown in Fig. 1. Under constant pressure, the transmission increases with sintering 


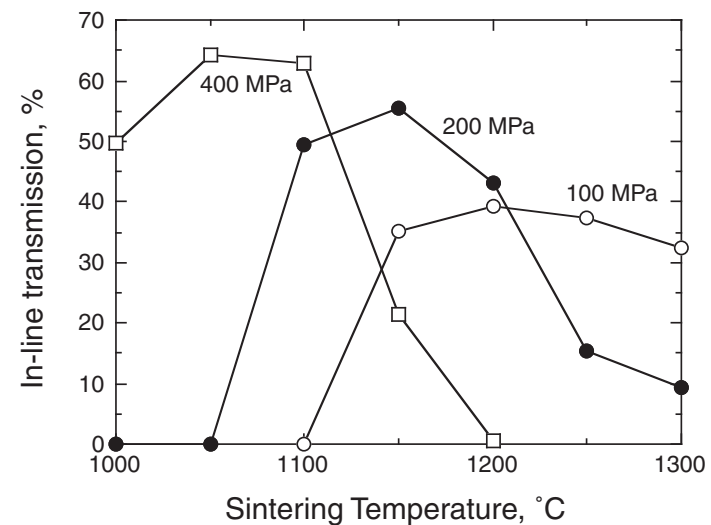

Fig. 1. In-line transmission of the alumina sintered at various sintering temperatures and pressures.

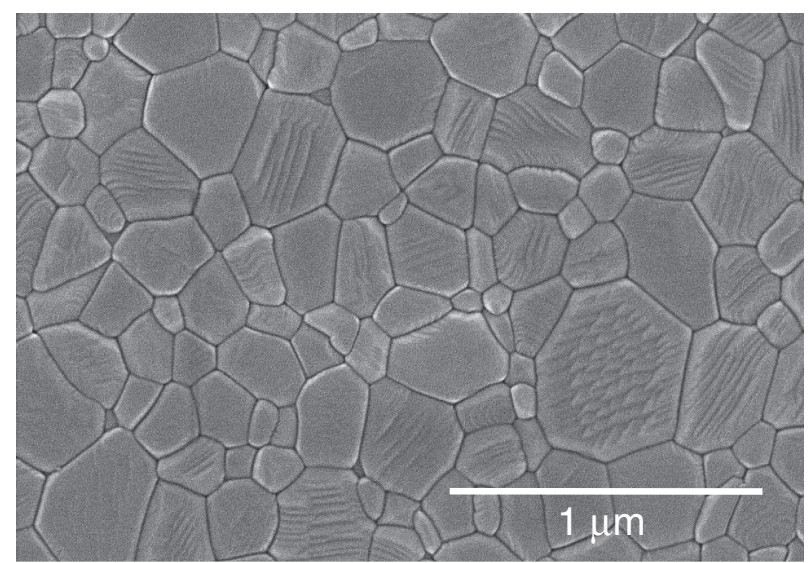

Fig. 2. Microstructure of the alumina sintered at $1100^{\circ} \mathrm{C}$ and at $400 \mathrm{MPa}$.

temperature due to increasing densification, and shows a peak. With an increase in the pressure, the sintering temperature for peak transmission is lowered and the value of peak transmission increases. That is, high-pressure sintering at low temperatures enables to obtain highly transparent alumina. The maximum in-line transmission for the $\mathrm{MgO}$-doped alumina was obtained by sintering at $1050^{\circ} \mathrm{C}$ and at $400 \mathrm{MPa}$. The transmission at a wavelength of $640 \mathrm{~nm}$ is $64 \%$ for $1-\mathrm{mm}$ thick sample, which corresponds to $69 \%$ for $0.8-\mathrm{mm}$ thickness when the transmission value is converted using the Lambert-Beer law. An in-line transmission of $69 \%$ is the highest value for alumina obtained by SPS, and is slightly lower than the maximum value (72\%) attained by HIP. ${ }^{9), 10)}$

For highly transparent alumina, extremely low porosities and fine grain sizes are necessary and hence densification at low temperatures is indispensable. In the present study, such microstructure for high transmission was achieved by applying high pressures. The pressures $>400 \mathrm{MPa}$ may result in the in-line transmissions higher than $69 \%$. Figure 2 represents the microstructure of the alumina sintered at $1100^{\circ} \mathrm{C}$ and at $400 \mathrm{MPa}$ (in-line transmission of 63\%). It should be noted, however, that the application of high pressure restricts the available sample size and also makes the microstructure sensitive to the sintering temperature. As shown in Fig. 1, the decrease in the transmission at high temperature region becomes steeper with an increase in the applied pressure. At $400 \mathrm{MPa}$, the highly transparent alumina sintered at $1050^{\circ} \mathrm{C}$ becomes opaque (almost zero in-line trans-

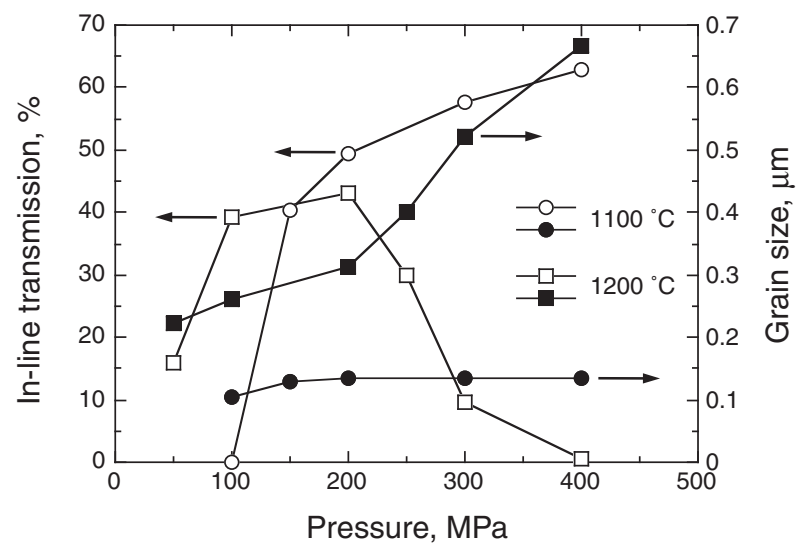

Fig. 3. In-line transmission and grain size of the alumina sintered at 1100 and $1200^{\circ} \mathrm{C}$.

mission) when it is sintered at $1200^{\circ} \mathrm{C}$. Under lower pressures, the decreasing rate is slow, so that transparent alumina (but with lower transmission) can be obtained in a wider range of the sintering temperature.

In Fig. 1, the decrease in the transmission at high temperature region is due to grain growth. At $400 \mathrm{MPa}$, the grain size for the alumina sintered at 1100 and $1200^{\circ} \mathrm{C}$ is 0.14 and $0.67 \mu \mathrm{m}$, respectively. The increase in the sintering temperature by $100^{\circ} \mathrm{C}$ resulted in 4 times larger grains. The large grains scatter a light and reduce the in-line transmission. Under lower pressures, however, the grain growth is less significant. For example, at $200 \mathrm{MPa}$, the grain size for the alumina sintered at 1100 and $1200^{\circ} \mathrm{C}$ is 0.14 and $0.31 \mu \mathrm{m}$, respectively. At $1200^{\circ} \mathrm{C}$, the grain size at $200 \mathrm{MPa}$ is a half that at $400 \mathrm{MPa}$. Apparently, the pressure effect on grain growth is significant at $1200^{\circ} \mathrm{C}$, but not at $1100^{\circ} \mathrm{C}$.

Figure 3 represents the pressure effect on transmission and grain growth. At $1100^{\circ} \mathrm{C}$, the increasing pressure up to $400 \mathrm{MPa}$ increases the transmission and has a little effect on the grain size. This indicates that at $1100^{\circ} \mathrm{C}$, the applied pressure increases the final density without noticeable grain growth. At $1200^{\circ} \mathrm{C}$, however, the transmission increases with the increasing pressure up to $200 \mathrm{MPa}$, and then decreases. The decreasing transmission at pressures $>200 \mathrm{MPa}$ can be attributed to the grain and pore growth. As shown in Fig. 3, grain growth becomes significant at $>200 \mathrm{MPa}$. In addition, our previous study reported that grain growth in the high-density region is accompanied by pore growth. ${ }^{3)}$ It is considered that the accelerated grain/pore growth at $1200^{\circ} \mathrm{C}$ made the alumina opaque, despite the high-pressure sintering.

On the pressure effect during SPS, contradictory results have been reported. Whereas Munir et al. ${ }^{13)}$ and Quach et al. ${ }^{14)}$ observed no pressure effect on grain growth for cubic zirconia, Bakshi et al. ${ }^{15)}$ observed an increase in grain size with increasing pressure for $\mathrm{TaC}$. In the present study for alumina, however, both phenomena appeared: the negligible pressure effect on grain growth at low temperature $\left(1100^{\circ} \mathrm{C}\right)$ and the significant pressure effect of accelerating grain growth at high temperature $\left(1200^{\circ} \mathrm{C}\right)$. According to the model of grain-boundary free volume, ${ }^{16}$ ) compressive pressure reduces the free volume and the transfer of atoms between grain boundaries, resulting in a corresponding decrease in the grain-boundary mobility. It was also reported experimentally that hydrostatic pressing of fully densified polycrystals reduces the grain-growth rate. ${ }^{17)}$ The free-volume model therefore cannot explain the accelerated grain growth of the present alumina under compressive pressure at $1200^{\circ} \mathrm{C}$. 


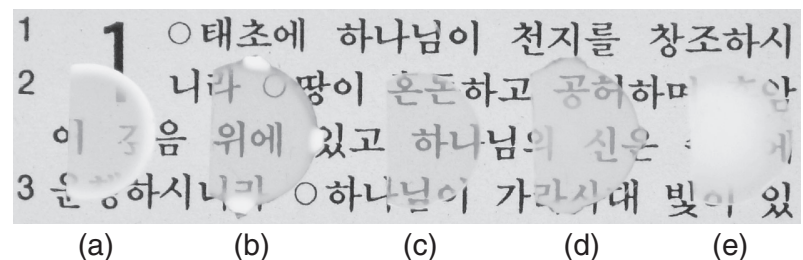

Fig. 4. Alumina samples sintered at $400 \mathrm{MPa}$ and at (a) 1000, (b) 1050 , (c) 1100, (d) 1150 and (e) $1200^{\circ} \mathrm{C}$.

During sintering, however, most densification occurs by grainboundary sliding or deformation. ${ }^{18)}$ Since full densification of powder compacts requires a reduction in volume by $40-50 \%$ conventionally, the densification cannot be achieved without grainboundary sliding when the powder particles remain equiaxed. Grain-boundary sliding at high temperatures is known to cause accelerated grain growth, namely dynamic grain growth, ${ }^{19)-21)}$ and the pressure applied during sintering increases the sliding or deformation rate. During sintering, the pressure effect of suppressing grain growth without grain-boundary sliding (the free-volume model) should therefore be considered along with the deformation effect inducing dynamic grain growth. The significant pressure effect on grain growth at $1200^{\circ} \mathrm{C}$ can be attributed to the dynamic grain growth caused by the grain-boundary sliding during sintering, and the negligible pressure effect at $1100^{\circ} \mathrm{C}$ to low grainboundary mobility. It is hence considered that the pressure effect on both grain growth and transmission becomes significant at temperatures where the grain-boundary mobility is sufficiently high.

The appearance of the alumina sintered at $400 \mathrm{MPa}$ is shown in Fig. 4. The alumina samples are placed $24 \mathrm{~mm}$ above the text, and are transparent when sintered at $<1200^{\circ} \mathrm{C}$. For the alumina sintered at $1000^{\circ} \mathrm{C}$, only the central part is transparent and the periphery is opaque, indicating that densification proceeded from the inside region. This is different from the observation of Grasso et al. ${ }^{22)}$ for the same alumina powder. Under a pressure of $80 \mathrm{MPa}$, they observed that densification proceeded from the periphery. In their experiments, however, the heating rate is $100^{\circ} \mathrm{C} / \mathrm{min}$, which is 10 times higher than the present one. High heating rates during SPS of non-conducting powder such as alumina induces large temperature difference between the graphite die and the powder during heating, and accordingly densification proceeds from the periphery. In the present study, it is considered that the temperature distribution is quite uniform owing to the low heating rate, so that the densification proceeded mainly by the applied pressure from the central part.

At the sintering temperatures of $1050-1100^{\circ} \mathrm{C}$, the opaque periphery disappeared, as shown in Fig. 4. Uniformly densified alumina was fabricated and the in-line transmission is close to the maximum value attained by HIP. At higher sintering temperatures, however, rapid grain growth occurred in the inside region and made the region opaque. As shown in Fig. 4(e), the alumina sintered at $1200^{\circ} \mathrm{C}$ exhibits the opaque inside region and the transparent periphery, which is opposite to the alumina sintered at $1000^{\circ} \mathrm{C}$. The rapid grain growth in the inside region was also observed in our previous experiments for pure alumina. ${ }^{3)}$ Though the rapid grain growth in the inside region must be related to high grain-boundary mobility, the identification of the relating mechanisms are difficult at this moment and detailed examination is required.

\section{Conclusions}

Using high-pressure SPS, highly transparent alumina was obtained; for the $\mathrm{MgO}$-doped alumina sintered at $1050^{\circ} \mathrm{C}$ and at $400 \mathrm{MPa}$, the in-line transmission is close to the maximum transmission attained by HIP. With increasing pressure up to $400 \mathrm{MPa}$, the transmission increases for the alumina sintered at $1100^{\circ} \mathrm{C}$, but shows a peak and subsequently decreases at $1200^{\circ} \mathrm{C}$. Microstructural observation showed that the accelerated grain growth under high pressures had lowered the transmission of the alumina sintered at $1200^{\circ} \mathrm{C}$. It is considered that the pressure effect on both grain growth and transmission is significant at temperatures where the grain-boundary mobility is sufficiently high.

Acknowledgments This work was partly supported by the Grant-in Aid for Scientific Research (B-21360328) from the Ministry of Education, Culture, Sports, Science and Technology, Japan.

\section{References}

1) B.-N. Kim, K. Hiraga, K. Morita and H. Yoshida, Scr. Mater., 57, 607-610 (2007).

2) B.-N. Kim, K. Hiraga, K. Morita and H. Yoshida, J. Eur. Ceram. Soc., 29, 323-327 (2009).

3) B.-N. Kim, K. Hiraga, K. Morita, H. Yoshida, T. Miyazaki and Y. Kagawa, Acta Mater, 57, 1319-1326 (2009).

4) B.-N. Kim, K. Hiraga, K. Morita, H. Yoshida and Y. Kagawa, Acta Mater., 58, 4527-4535 (2010).

5) G. Bernard-Granger, C. Guizard and A. Addad, J. Am. Ceram. Soc., 91, 1703-1706 (2008).

6) M. Stuer, Z. Zhao, U. Aschauer and P. Bowen, J. Eur. Ceram. Soc., 30, 1335-1343 (2010).

7) X. Jin, L. Gao and J. Sun, J. Am. Ceram. Soc., 93, 1232-1236 (2010).

8) S. Grasso, B.-N. Kim, C. Hu, G. Maizza and Y. Sakka, J. Am. Ceram. Soc., 93, 2460-2462 (2010).

9) R. Apetz and M. P. B. van Bruggen, J. Am. Ceram. Soc., 86, 480-486 (2003).

10) A. Krell, J. Klimke and T. Hutzler, J. Eur. Ceram. Soc., 29, 275-281 (2009).

11) S. J. Bennison and M. P. Harmer, J. Am. Ceram. Soc., 66, C90-C92 (1983).

12) H. B. Zhang, B.-N. Kim, K. Morita, H. Yoshida, J. H. Lim and K. Hiraga, J. Alloys Compd., 508, 196-199 (2010).

13) Z. A. Munir, U. Anselmi-Tamburini and M. Ohyanagi, J. Mater. Sci., 41, 763-777 (2006).

14) D. V. Quach, H. Avila-Paredes, S. Kim, M. Martin and Z. A. Munir, Acta Mater., 58, 5022-5030 (2010).

15) S. R. Bakshi, V. Musaramthota, D. Lahiri, V. Singh, S. Seal and A. Agarwal, Mater. Sci. Eng., A, 528, 1287-1295 (2011).

16) J. H. Perepezko and T. B. Massalski, Scr. Metall., 6, 743-752 (1972).

17) H. Hahn and H. Gleiter, Scr. Metall., 13, 3-6 (1979).

18) K.-S. Oh, D.-Y. Kim and S.-J. Cho, J. Am. Ceram. Soc., 78, 2537-2540 (1995).

19) M. A. Clark and T. H. Alden, Acta Metall., 21, 1195-1206 (1973).

20) D. S. Wilkinson and C. H. Cáceres, Acta Metall., 32, 13351345 (1984).

21) B.-N. Kim, K. Hiraga, Y. Sakka and B.-W. Ahn, Acta Mater., 47, 3433-3439 (1999).

22) S. Grasso, C. Hu, G. Maizza, B.-N. Kim and Y. Sakka, J. Am. Ceram. Soc., 94, 1405-1409 (2011). 